\title{
NGHIÊN CÚU ĐA TRUNG TÂM ĐÁNH GIÁ ĐƯỜNG CONG ĐÀO TẠO VÀ KẾT QUẢ LÂM SÀNG CỦA PHÃ̂ THUẠT NỘI SOI TOÀN BỘ VÁ THÔNG LIÊN NHĨ KHÔNG ROBOT HỖ TRợ
}

\author{
Đặng Quang Huy*, Nguyễn Công Hưu***, Nguyễn Minh Ngọ**, Lê Ngoc Thành**
}

\section{TÓM TẮT}

125 bệnh nhân ( 89 bệnh nhân nữ; tuổi trung bình, 31,6 \pm 18,7 tuổi; khoảng tuổi, 3-72 tuổi) với chẩn đoán TLN lỗ thứ phát được lựa chọn vào nghiên cứu. Sử dụng 3 trocar $5 \mathrm{~mm}$ và 1 trocar $12 \mathrm{~mm}$; chỉ thắt tĩnh mạch chủ (TMC) trên. Khoang màng tim và màng phổi được làm đầy bằng $\mathrm{CO} 2$. Tất cả lỗ thông được đóng sử dụng miếng vá nhân tạo, khâu vắt; hở van ba lá (VBL) được sửa sử dụng vòng van hoặc theo phương pháp DeVega cải tiến; tĩnh mạch phổi lạc chỗ được sửa dẫn máu về nhĩ trái. Tất cả bệnh nhân được phẫu thuật bởi một phẫu thuật viên trong điều kiện tim đập. Không có biến chứng nặng và không có trường hợp tử vong. Không có trường hợp nào có TLN tồn lưu được ghi nhận. Dựa vào hình thức sửa $\mathrm{VBL}$, bệnh nhân được chia thành 3 nhóm: nhóm I (không sửa $\mathrm{VBL}$ ), nhóm II (sửa VBL theo phương pháp DeVega cải tiến), và nhóm III(sử dụng vòng van). Ghi nhận đường cong đào tạo có ý nghĩa về thời gian phẫu thuật, thời gian chạy máy ở mỗi nhóm. Thời gian phẫu thuật và thời gian chạy máy ở nhóm I lần lượt là: $\mathrm{y}=400-52$ $\ln (\mathrm{x})\left(\mathrm{r}^{2}=0.616\right)$ and $\mathrm{y}=293-51 \ln (\mathrm{x})\left(\mathrm{r}^{2}=\right.$ 0.852); ở nhóm II lần lượt là: $\mathrm{y}=271-29 \ln (\mathrm{x})$ $\left(\mathrm{r}^{2}=0.236\right)$ and $\mathrm{y}=178-34 \ln (\mathrm{x})\left(\mathrm{r}^{2}=\right.$ 0.659 ); ̛̛̉ nhóm III lần lượt là: $\mathrm{y}=318-44 \ln (\mathrm{x})$ $\left(\mathrm{r}^{2}=0.565\right)$ and $\mathrm{y}=184-29 \ln (\mathrm{x})\left(\mathrm{r}^{2}=0.685\right)$. Thời gian nằm hồi sức trung bình là $25,3 \pm$ 20,7giờ. Bệnh nhân được ra viện sau mổ 8 ngày.

Từ khóa: sửa van ba lá sử dụng vòng van, vá thông liên nhĩ, phẫu thuật nội soi toàn bộ.
MULTICENTER STUDY TO ASSESS

LEARNING CURVE AND CLINICAL OUTCOME OF TOTALLY ENDOSCOPIC SURGERY FOR ATRIAL SEPTAL DEFECT REPAIR WITHOUT ROBOTIC

\section{ASSISTANCE*}

\section{SUMMARY}

125 patients (89 female patients; average age, $31.6 \pm 18.7$ years; age range, 3-72 years) with secundum-type ASDs were selected for this study. Three 5-mm trocars and one 12-mm trocar were used; only the superior vena cava was snared. The pleural and pericardial cavities were filled with $\mathrm{CO} 2$. All ASDs were closed using artificial patch, continuous suture; tricuspid valve regurgitations (TVR) were repaired and the anomalous pulmonary veins were drained to the left atrium. Surgeries were performed by one surgeon on the beating heart. No major complications or deaths occurred. No residual shunt was detected. Patients were divided into three groups: group I (without tricuspid valve repair), group II (DeVega), and group III (Ring annuloplasty). There were significant learning curves for the operation time and $\mathrm{CPB}$ time in

* Trung tâm tim mạch, Bệnh viện tim Hà Nội

** Trung tâm tim mach, Bệnh viện $E$

Người chịu trách nhiệm khoa học: TS. Nguyến Công Hưu

Ngày nhận bài: 01/07/2019 - Ngày Cho Phép Đăng: 20/07/2019

Phản Biện Khoa họ: PGS.TS. Đặng Ngọc Hùng GS.TS. Lê Ngoc Thành 
each group. In without tricuspid valve repair group, operation time and CPB time were: $\mathrm{y}=$ $400-52 \ln (\mathrm{x})\left(\mathrm{r}^{2}=0.616\right)$ and $\mathrm{y}=293-51 \ln (\mathrm{x})$ $\left(r^{2}=0.852\right)$, respectively. In DeVega group, operation time and CPB time were: $y=271-29$ $\ln (\mathrm{x})\left(\mathrm{r}^{2}=0.236\right)$ and $\mathrm{y}=178-34 \ln (\mathrm{x})\left(\mathrm{r}^{2}=\right.$ 0.659), respectively. In Ring annuloplasty group, operation time and CPB time were: $\mathrm{y}=318-44$ $\ln (\mathrm{x})\left(\mathrm{r}^{2}=0.565\right)$ and $\mathrm{y}=184-29 \ln (\mathrm{x})\left(\mathrm{r}^{2}=\right.$ $0.685)$, respectively. The length of stay in the intensive care unit was $25,3 \pm 20,7$ hours. Patients were discharged from the hospital 8 days after the operation.

Keywords: tricuspid ring annuloplasty, ASD closure, totally endoscopic surgery.

\section{I. ĐẶT VẤN ĐỀ}

Trong hơn 2 thập niên trở lại đây, phẫu thuật nội soi toàn bộ (PTNSTB) đã trở thành lựa chọn hàng đầu cho những bệnh nhân thông liên nhĩ (TLN) không điều trị được bằng phương pháp tim mạch can thiệp. Nhờ sự thuận lợi trong thao tác kỹ thuật, PTNSTB có hỗ trợ của robot sửa TLN đã được ứng dụng rộng rãi và có nhiều nghiên cứu lâu dài chứng minh tính an toàn, hiệu quả của phương pháp[1-4]. Đến thời điểm này, có ít báo cáo về PTNSTB không robot hỗ trợ sửa TLN với số lượng bệnh nhân không lớn; đồng thời chưa có sự thống nhất về phương pháp phẫu thuật giữa các trung tâm [-7]. Trong bài báo này, chúng tôi xây dựng phương pháp nghiên cứu nhằm mục đích đánh giá kết quả lâm sàng và đường cong đào tạo của phương pháp riêng do chúng tôi phát triển.

\section{II. ĐỐI TƯợng VÀ PHƯƠNG PHÁP NGHIÊN CÚU}

\subsection{Lựa chọn bệnh nhân}

Trong khoảng thời gian từ tháng 5/2016 đến tháng 6/2019, 125bệnh nhân TLN lỗ thứ phát được áp dụng phương pháp PTNSTB không robot hỗ trợ được lựa chọn vào nghiên cứu. Tất cả phẫu thuật được thực hiện bởi cùng một phẫu thuật viên tại hai trung tâm tim mạch lớn ở hai khoảng thời gian khác nhau: Trung tâm tim mạch, Bệnh viện $\mathrm{E}$ trong khoảng thời gian từ tháng $5 / 2016$ đến tháng $2 / 2018$ và Trung tâm phẫu thuật tim người lớn, Bệnh viện tim Hà Nội từ tháng 3/2018 đến tháng 6/2019.

Tiêu chuẩn lựa chọn đối tượng nghiên cứu bao gồm: (1) bệnh nhân có cân nặng từ 13,5 kg trở lên, (2) TLN lỗ thứ phát kèm theo hở van ba lá (VBL) hoặc tĩnh mạch phổi (TMP) lạc chỗ bán phần, và (3) bệnh nhân có các bệnh lý trong tim khác kèm theo, như: còn ống động mạch, hẹp van động mạch phổi (ĐMP), hẹp động mạch vành có thể điều trị trước phẫu thuật bằng tim mạch can thiệp.

Tiêu chuẩn loại trừ bao gồm: (1) bệnh nhân có cân nặng < 13,5kg, (2) bệnh nhân tăng áp lực ĐMP nặng không còn chỉ định phẫu thuật, (3) bệnh nhân có các bệnh lý tim mạch khác kèm theo đòi hỏi phải sửa chữa bằng phẫu thuật, như: thông liên thất, thông sàn nhĩ thất, tứ chứng Fallot..., (4) bệnh nhân có bệnh lý phổi màng phổi bên phải, như: tiền sử phẫu thuật phổi bên phải, lao màng phổi, bệnh phổi tắc nghẽn mạn tính nặng, và (5) bệnh nhân có mức xơ vữa từ vừa đến nhiều của động mạch chủ (ĐMC), động mạch (ĐM) chậu và ĐM đùi chung hai bên (được khảo 
sát bằng siêu âm mạch hoặc chụp cắt lớp đa dãy). mổ được trình bày trong Bảng 1 . Phương pháp Các thông số nhân trắc học (tuổi, cân nặng, phẫu thuật được hội đồng khoa học bệnh viện diện tích da, kích thước lỗ thông) trước mổ, các thông qua và được sự đồng thuận của bệnh nhân đặc điểm về bệnh học và nguyên nhân chỉ định và gia đình.

Bảng 1: Các thông số nhân trắc học và thông số trước mổ $(n=125)$

\begin{tabular}{|c|c|c|}
\hline \multicolumn{2}{|l|}{ Tuổi (năm) } & $31,6 \pm 18,7(3-72)$ \\
\hline \multicolumn{2}{|l|}{ Giới (nam/nữ) } & $1: 2,5$ \\
\hline \multicolumn{2}{|l|}{ Cân nặng (kg) } & $42,7 \pm 14,7(13,5-71)$ \\
\hline \multicolumn{2}{|l|}{ Diện tích da $\left(\mathrm{m}^{2}\right)$} & $1,316 \pm 0,318(0,6-1,85)$ \\
\hline \multicolumn{3}{|l|}{ Loại bệnh } \\
\hline & TLN thứ phát đơn thuần & 72 \\
\hline & TLN kèm hở VBL vừa/ nhiều & 48 \\
\hline & TLN kèm TMP lạc chỗ bán phần & 5 \\
\hline \multicolumn{2}{|l|}{ ĐK lỗ thông (mm) } & $30,9 \pm 6,8(13-45)$ \\
\hline \multicolumn{2}{|l|}{ Áp lực ĐMP (mmHg) } & $54,5 \pm 18,2(28-110)$ \\
\hline \multicolumn{2}{|l|}{ Đường kính thất phải } & \\
\hline \multicolumn{3}{|c|}{ Nguyên nhân chỉ định phẫu thuật } \\
\hline & Lỗ TLN lớn & 30 \\
\hline & Bịt dù thất bại & 8 \\
\hline & Gờ lỗ thông không phù hợp can thiệp & 56 \\
\hline & TMP lạc chỗ bán phần & 5 \\
\hline & Hở VBL nhiều & 26 \\
\hline
\end{tabular}

\subsection{Phương pháp phẫu thuật}

Bệnh nhân được gây mê bằng ống nội khí quản một nòng. Bác sĩ gây mê đặt catheter tĩnh mạch trung ương vào tĩnh mạch $(\mathrm{TM})$ cảnh trong trái và đặt sẵn một kim luồn vào $\mathrm{TM}$ cảnh trong phải, tất cả được thực hiện vô trùng.Bệnh nhân được đặt tư thế nằm nghiêng trái $20-30^{\circ}$, hai tay xuôi theo thân người, đầu nghiêng về phía bên trái bộc lộ kim luồn đã được đặt sẵn. Phẫu thuật viên vẽ sẵn vị trí dự định đặt các lỗ trocar.

Để thiết lập tuần hoàn ngoại vi chúng tôi 
tạo một đường rạch dài $2 \mathrm{~cm}$ ngang ở nếp bẹn bên phải, bộc lộ ĐM đùi chung và $\mathrm{TM}$ đùi. Ở những $\mathrm{BN}$ có cân nặng $\geq 15 \mathrm{~kg}$, chúng tôi thiết lập đường động mạch một cách gián tiếp vào ĐM đùi chung qua một đoạn mạch Dacron (Vascutek Terumo, Bangkok, Thailand). Trong khi đoạn mạch Dacron số 8 được sử dụng cho những bệnh nhân có cân nặng $\geq 25 \mathrm{~kg}$,đoạn mạch Dacron số 6 được sử dụng cho những bệnh nhân có cân nặng từ 15 đến $25 \mathrm{~kg}$. Ống thông $\mathrm{TMC}$ trên và $\mathrm{TMC}$ dưới được đặt qua $\mathrm{TM}$ cảnh trong phải và $\mathrm{TM}$ đùi bằng phương pháp Sheldinger (Hình 1A). Chúng tôi kiểm tra đường $Đ M$ bằng cách chạy máy thử, nếu với toàn bộ lưu lượng mà áp lực đường $\mathrm{ĐM}<$ $220 \mathrm{mmHg}$ thì chấp nhận được. Nếu áp lực đường ĐM tăng quá 220mmHg sẽ đặt một đường ĐM phụ với mục đích giảm áp vào ĐM đùi bên trái; ống thông $\mathrm{ĐM}$ phụ này có kích thước nhỏ hơn 4Fr so với kích thước bình thường (dựa trên cân nặng của bệnh nhân) (Hình $1 \mathrm{~B}$ ). Ở những $\mathrm{BN}$ nhỏ tuổi, cân nặng từ $13,5 \mathrm{~kg}$ đến $15 \mathrm{~kg}$, chúng tôi đặt ống thông ĐM trực tiếp vào ĐM đùi hai bên, chọn ống thông có kích thước nhỏ hơn 2-4Fr so với cân nặng của $\mathrm{BN}$ (Hình $1 \mathrm{C}$ ).

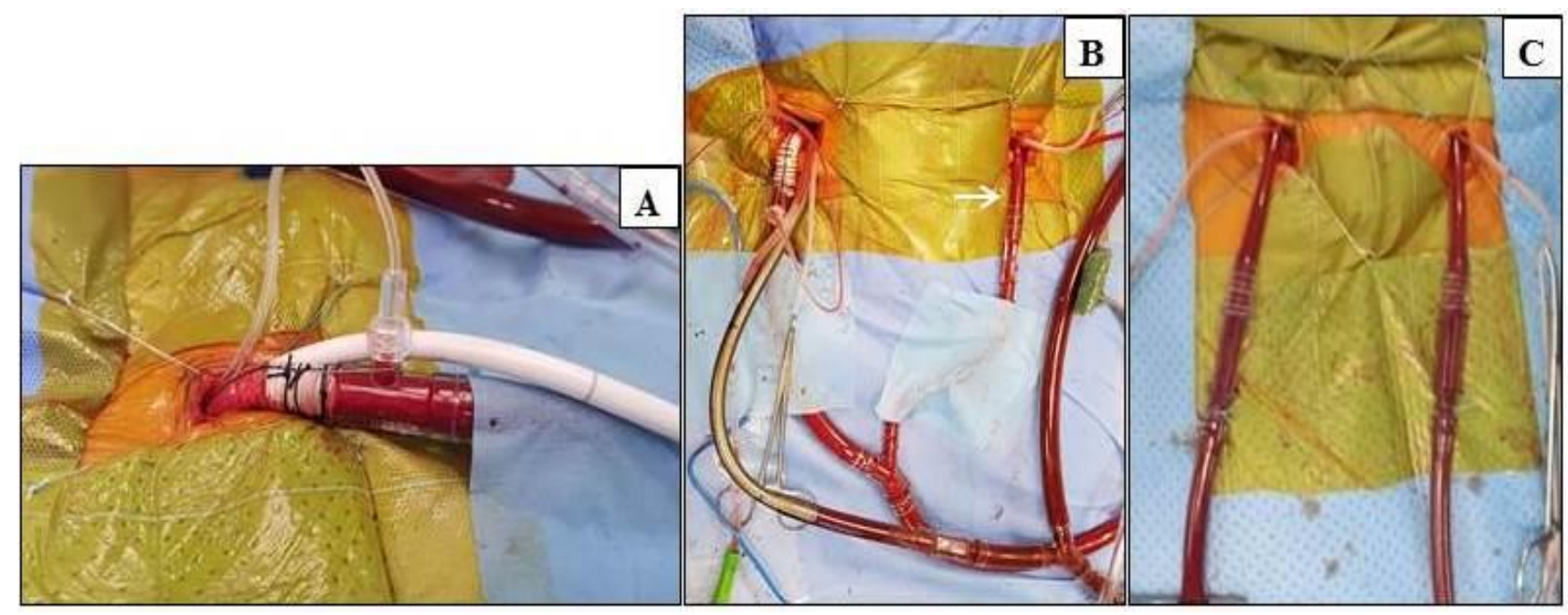

Hình 1, (A) Ống thông ĐM đùi được thiết lập gián tiếp qua một đoạn mạch nhân tạo Dacron số 8, ống thông $T M C$ duới được đặt qua TM đùi theo phuơng pháp Seldinger; (B) khi áp lục đường $Đ M>220 \mathrm{mmHg}$, môt ống thông ĐM kích thuớc nhỏ (mũi tên mầu trắng) được đặt trục tiếp vào ĐM đùi chung trái nhằm muc đich giảm áp lục; và (C) ở nhũng bệnh nhi có cân nặng tù 13,5kg đến $15 \mathrm{~kg}$, hai ống thông ĐM có kích thước nhỏ được đặt trục tiếp vào ĐM đùi chung hai bên.ĐM: động mạch, TM: tĩnh mạch, TMC: tĩnh mạch chủ.

Bốn trocar được thiết lập lần lượt: 01 trocar $12 \mathrm{~mm}$ tại khoang liên sườn (KLS) $\mathrm{V}$ đường nách trước là tay làm việc chính (cho các dụng cụ: phẫu tích, kẹp kim, dao điện, máy hút bỏ), 01 trocar $5 \mathrm{~mm}$ tại KLS IV đường nách giữa là tay làm việc phụ (cho phẫu tích), 01 trocar $5 \mathrm{~mm}$ tại KLS $\mathrm{V}$ đường nách giữa (cho đèn nội soi với đường $\mathrm{CO} 2$ được kết nối qua van có khóa) và 01 trocar $5 \mathrm{~mm}$ tại KLS VI đường nách giữa (cho đường hút máu về) (Hình 2). 


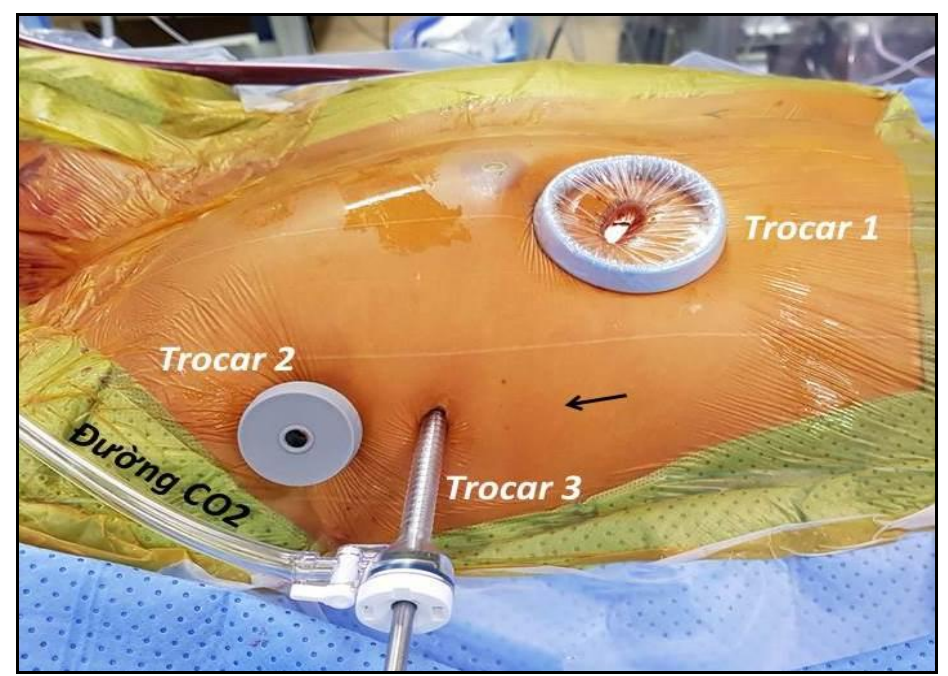

Hình 2, Cách thức đặt các trocar. Trocar $1(12 \mathrm{~mm})$ là cổng cho tay làm việc chính. Ba trocar $5 \mathrm{~mm}$ bao gồm: trocar 2 là cổng cho tay làm việc phu, trocar 3 là cổng cho camera với đường bơm CO2 được kết nối qua một van có khóa, và trocar 4 tương úng với vị trí mũi tên cho đường hút máu về.

Sau khi vào đến khoang màng phổi, tuần hoàn ngoài cơ thể bắt đầu hoạt động để làm xẹp phổi phải. Màng tim được mở song song và cách thành ngực trước một khoảng $1,5 \mathrm{~cm}$. Khoang màng tim và màng phổi được làm đầy bởi $\mathrm{CO} 2$ với tốc độ bơm được duy trì 2 lít/phút. Người bệnh được đặt nằm ở tư thế Trendelenburg. Sau khi đã thắt $\mathrm{TMC}$ trên, nhĩ phải (NP) được mở dọc theo rãnh liên nhĩ và khâu treo vào màng tim. Tim đập liên tục trong suốt quá trình mổ, máu về qua xoang vành, các lỗ đổ trực tiếp trên thành $\mathrm{NP}$ và lỗ $\mathrm{TMC}$
dưới.Đường hút máu về (qua trocar 4) cùng với duy trì áp lực hút âm từ $20-40 \mathrm{mmHg}$ của đường TM giúp tạo phẫu trường sạch máu. Các mốc giải phẫu cần xác định trong quá trình mổ gồm: lỗ van ba lá, lỗ xoang vành, lỗ TMC dưới và các lỗ TMP phải. Tất cả lỗ thông được đóng bằng miếng vá nhân tạo, khâu vắt. TMP lạc chỗ được tạo đường hầm trong tim dẫn máu về nhĩ trái qua lỗ TLN. Những trường hợp van ba lá hở vừa - nhiều trước mổ được sửa theo phương pháp Devega hoặc đặt vòng van tùy theo mức độ giãn của vòng van.

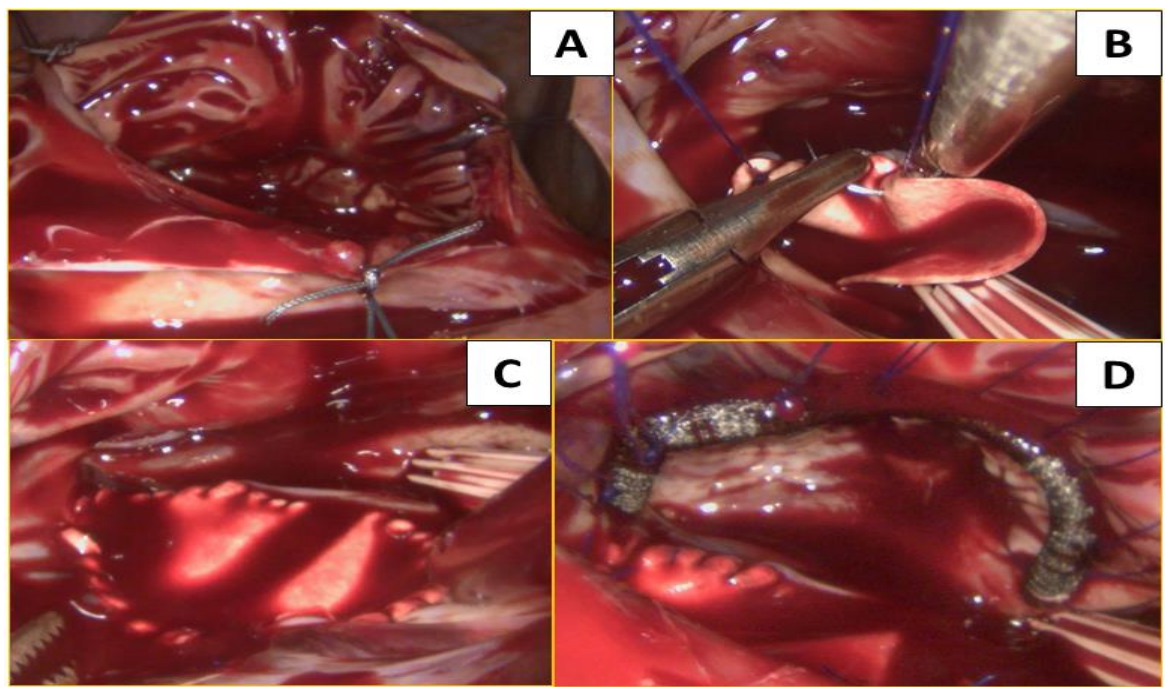

Hình 3. Kỹ thuật vá thông liên nhĩ và sưa van ba lá bằng phưong pháp nội soi toàn bộ. A, Nhĩ phải được mở và khâu treo vào màng tim sau khi làm đầy khoang màng phổi và màng tim bằng CO2; $\boldsymbol{B}$, sủ dụng miếng vá nhân tạo Neuropatch để đóng lỗ thông liên nhĩ; $\boldsymbol{C}$, miếng vá sau khi đã hoàn thành; $\boldsymbol{D}$, vòng van ba lá được đặt vào đúng vị trí. 
Đường mở NP được đóng hai lớp. Tim được làm đầy sau khi thả thắt $\mathrm{TMC}$ trên, tư thế đầu bằng và kiểm tra cầm máu kỹ, màng tim được đóng mũi rời. Ngừng tuần hoàn ngoài cơ thể sau khi đặt dẫn lưu màng tim và dẫn lưu màng phổi. Tất cả bệnh nhân sau mổ được kiểm tra bằng siêu âm qua thành ngực trước khi ra viện.

Bảng 2. Các thông số về thiết lập tuần hoàn ngoài co thể ngoại vi (n=125)

\begin{tabular}{|c|c|}
\hline Ống thông ĐM đùi ở bệnh nhân trưởng thành $(\geq 25 \mathrm{~kg})$ & 101 \\
\hline Qua đoạn mạch Dacron số 8, $\mathrm{n}$ & $14(13,9)$ \\
\hline Qua đoạn mạch Dacron số 8 + đường ĐM phụ, n, $(\%)$ & 20 \\
\hline Ống thông ĐM đùi ở bệnh nhân nhi (15kg $\rightarrow$ 25kg) & $12(60)$ \\
\hline Qua đoạn mạch Dacron số 6, $\mathrm{n}$ & 4 \\
\hline Qua đoạn mạch Dacron số 6 + đường ĐM phụ, n, $(\%)$ & Oặt ống thông động mạch đùi 2 bên $(13,5 \mathrm{~kg} \rightarrow 15 \mathrm{~kg}), \mathrm{n}$ \\
\hline
\end{tabular}

\subsection{Theo dõi sau mổ:}

Trong năm đầu sau mổ, bệnh nhân được hẹn khám lại ở các mốc thời gian: 1 tháng, 3 tháng, 6 tháng, và 1 năm. Sau đó người bệnh được hẹn khám 1 năm/ lần. Bệnh nhân được khám, đánh giá tình trạng sẹo mổ, sự cân đối giữa hai ngực, tình trạng dị cảm quanh vị trí vết mổ ngực và đùi, sự hài lòng của gia đình và bệnh nhân về vị trí và kích thước sẹo mổ. Bệnh nhân được siêu âm tim qua thành ngực và siêu âm doppler mạch kiểm tra.

\subsection{Phân tích số liệu:}

Số liệu được tính ra trung bình \pm phương sai (S.D.) cho những biến định lượng và tính ra số lượng với tỉ lệ phần trăm cho những biến định tính. Số liệu được quản lý và phân tích bởi phần mềm SPSS 14.0.

\section{KẾT QUẢ}

Trong nghiên cứu của chúng tôi, 101 bệnh nhân được đặt ống thông ĐM đùi gián tiếp qua đoạn mạch Dacron số 8. Trong đó, 14 bệnh nhân (chiếm 13,9\%) có hiện tượng tăng áp lực đường ĐM đòi hỏi phải thiết lập đường ĐM phụ cho đùi bên đối diện. Trong nhóm bệnh nhi sử dụng đoạn mạch Dacron số 6,có tới 12/20 bệnh nhân (chiếm 60\%) gặp hiện tượng tăng áp lực đường ĐM đòi hỏi phải thiết lập đường $\mathrm{ĐM}$ phụ cho đùi bên đối diện. Chi tiết về cách thức thiết lập tuần hoàn ngoài cơ thể được trình bày trong Bảng 2.

Thời gian phẫu thuật và thời gian chạy máy trung bình lần lượt là $219,4 \pm 56,5$ phút và $116,5 \pm 44,7$ phút. Không bệnh nhân nào cần dùng thuốc trợ tim, vận mạch sau mổ. Thời gian thở máy trung bình 8 giờ; bệnh nhân nằm hồi sức trung bình 1 ngày và ra viện sau 8 ngày. Hầu hết bệnh nhân không cần dùng thuốc giảm đau từ ngày thứ 4 sau mổ. Chi tiết các thông số trong và sau mổ của bệnh nhân được trình bày trong Bảng 3.

Không có bệnh nhân tử vong trong giai đoạn nằm viện. Nhồi máu não cấp do huyết khối 
gặp ở một bệnh nhân rung nhĩ mạn tính tại thởi điểm hậu phẫu ngày thứ 3 với triệu chứng liệt nửa người và ý thức lơ mơ. Bệnh nhân được hút huyết khối ĐM não giữa bên trái và sau đó hồi phục hoàn toàn. Một bệnh nhân bị chảy máu nhiều sau mổ được chuyển mổ lại cưa dọc xương ức; nguồn chảy máu là do một nhánh nhỏ của ĐM liên thất trước ở vị trí mỏm tim bị xước rách. Nguyên nhân được xác định là do ống dẫn lưu màng tim bằng silicon cọ sát gây tổn thương. Một bệnh nhân còn tồn lưu TLN 3mm trước khi ra viện; lỗ thông tự đóng kín sau những lần khám lại 6 tháng, 1 năm. Chi tiết về biến chứng được liệt kê trong Bảng 4.

Bảng 3. Các thông số trong và sau mổ $(n=125)$

\begin{tabular}{|l|c|}
\hline Thời gian phẫu thuật, phút & $219,4 \pm 56,5(110-360)$ \\
\hline Thời gian chạy máy, phút & $116,5 \pm 44,7(49-220)$ \\
\hline Thời gian thở máy, giờ & $8,0 \pm 10,6$ \\
\hline Thời gian nằm hồi sức, giờ & $25,3 \pm 20,7$ \\
\hline Dẫn lưu trong 6 giờ đầu,ml & $45,4 \pm 40,0$ \\
\hline Dẫn lưu trong 24 giờ đầu,ml & $75,4 \pm 55,8$ \\
\hline Thời điểm không cần dùng thuốc giảm đau sau mổ,ngày & $4,3 \pm 1,1$ \\
\hline Thời gian nằm viện sau mổ,ngày & $8,5 \pm 3,7$ \\
\hline
\end{tabular}

Chúng tôi chia 125 bệnh nhân thành 3 nhóm dựa trên phương thức sửa $\mathrm{VBL}$, bao gồm: nhóm không sửa VBL (nhóm I), nhóm sửa VBL theo phương pháp DeVega cải tiến (nhóm II), và nhóm sửa VBL có sử dụng vòng van (nhóm III). Trong cả 3 nhóm đều ghi nhận đường cong đào tạo có ý nghĩa đối với hai thông số: thời gian phẫu thuật và thời gian chạy máy (Hình 4).
Thời gian khám lại trung bình là $16 \pm 8,2$ tháng (1-36 tháng). Tất cả bệnh nhân có lỗ thông được vá kín, không có hở VBL ở mức độ có ý nghĩa (vừa trở lên), không có trường hợp nào hẹp đường về của các TMP. Không có hẹp hoặc giả phồng ĐM đùi tại vị trí đặt ống thông được ghi nhận. Tất cả $\mathrm{BN}$ và gia đình đều rất hài lòng về hiệu quả và tính thẩm mỹ của sẹo mổ.

Bảng 4. Các biến chứng sau mổ $(n=125)$

\begin{tabular}{|l|c|}
\hline \multicolumn{1}{|c|}{ Loại biến chứng } & $\mathbf{n , ( \% )}$ \\
\hline Nhồi máu não do rung nhĩ & $1(0,8)$ \\
\hline Biến chứng mạch máu đùi & $0(0)$ \\
\hline Mở rộng vết mố, chuyển cưa xương ức & $0(0)$ \\
\hline Chảy máu mổ lại & $1(0,8)$ \\
\hline TLN tồn lưu nhỏ & $1(0,8)$ \\
\hline Tràn máu, tràn khí màng phổi & $2(1,6)$ \\
\hline Viêm phổi sau mổ & $2(1,6)$ \\
\hline Liệt hoành phải & $1(0,8)$ \\
\hline Chậm liền vết mổ & $2(1,6)$ \\
\hline
\end{tabular}



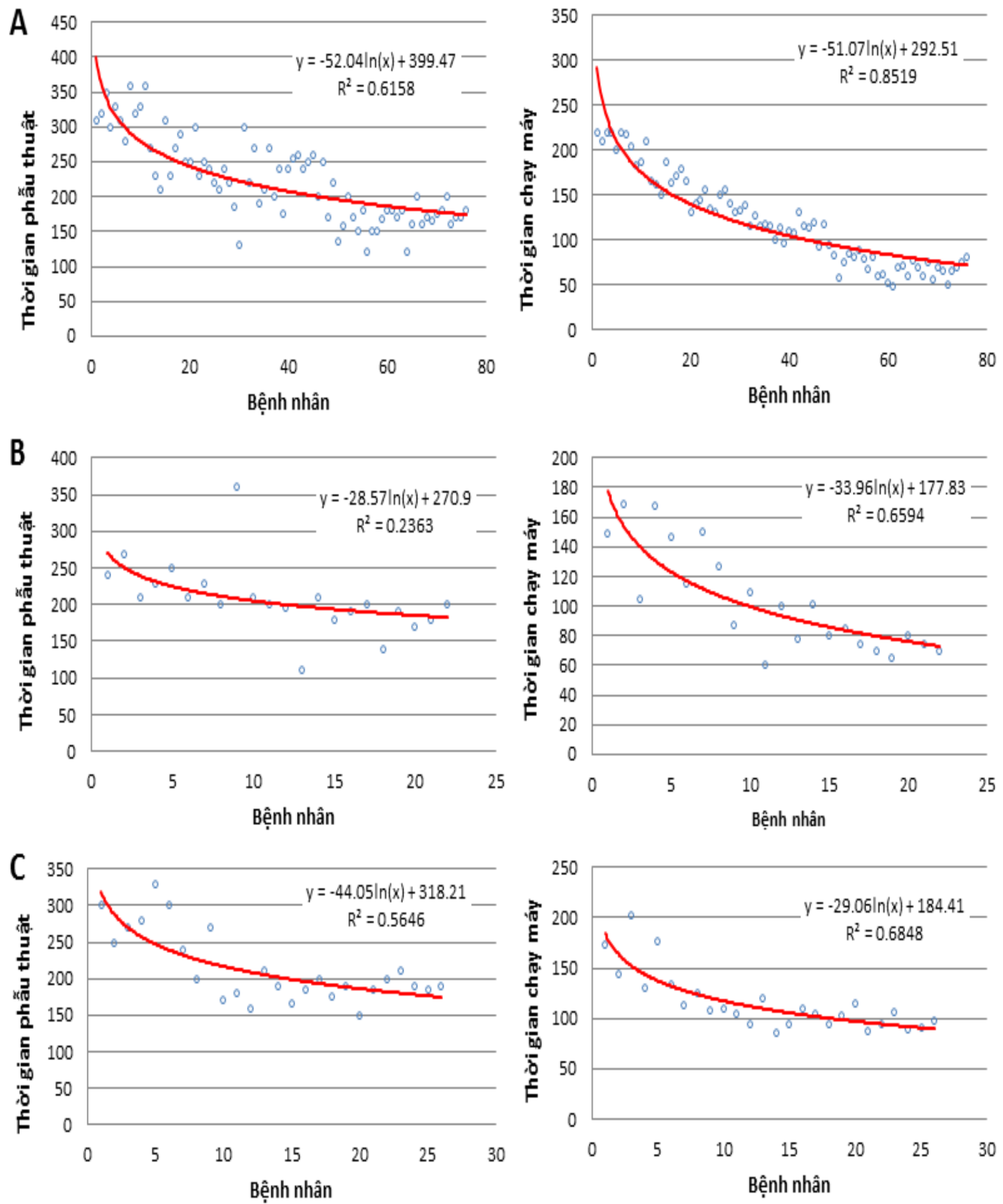

Hình 4, Đường cong đào tạo về thời gian phẫu thuật và thời gian chạy máy. A, nhóm không sứa van ba lá (nhóm I); B, nhóm sứa van ba lá theo phưong pháp DeVega cải tiến (nhóm II); $\boldsymbol{C}$, nhóm sứa van ba lá sủ dụng vòng van (nhóm III). 


\section{BÀN LUẬN}

TLN lỗ thứ phát là một trong những bệnh lý tim bẩm sinh (TBS) thường gặp nhất [8], và thường là lựa chọn đầu tiên để áp dụng những kỹ thuật hoặc phẫu thuật mới $[\underline{9}, \underline{10}]$. PTNSTB có hỗ trợ của robot đã trở thành thường quy trong điều trị bệnh TLN tại nhiều trung tâm tim mạch lớn trên thế giới [1-3] . Ở các nước đang phát triển (Trung Quốc, Việt Nam...), PTNSTB không có hỗ trợ của robot là lựa chọn phù hợp với khả năng chi trả của người bệnh và chi phí đào tạo thấp. Trong các báo cáo của mình, các tác giả Trung Quốc (sử dụng cùng một phương pháp phẫu thuật - tạm gọi là "Chinese method" ) đã chứng minh được phương pháp phẫu thuật của họ an toàn và hiệu quả khi áp dụng cho cả trẻ nhỏ và người trưởng thành, với thời gian theo dõi trung hạn[5, 7, 11, 12]. Tại Việt Nam, ca PTNSTB không hỗ trợ robot sửa bệnh TLN đầu tiên được tác giả Đặng Quang Huy thực hiện ở bệnh nhi 11 tuổi vào tháng 5/2016 [13]. Phương pháp phẫu thuật được sử dụng là phương pháp hoàn toàn mới gọi là "Vietnamese method". Từ đó đến nay, đã có 2 trung tâm phẫu thuật tim mạch lớn (bệnh viện $E$ và bệnh viện tim Hà Nội) thực hiện thường quy phẫu thuật này. Mặc dù đã có một vài báo cáo về kết quả ban đầu khả quan[13-16], trong nghiên cứu này, chúng tôi muốn đánh giá tính an toàn, hiệu quả với thời gian theo dõi trung hạn; đồng thời xác định đường cong đào tạo của phương pháp này.

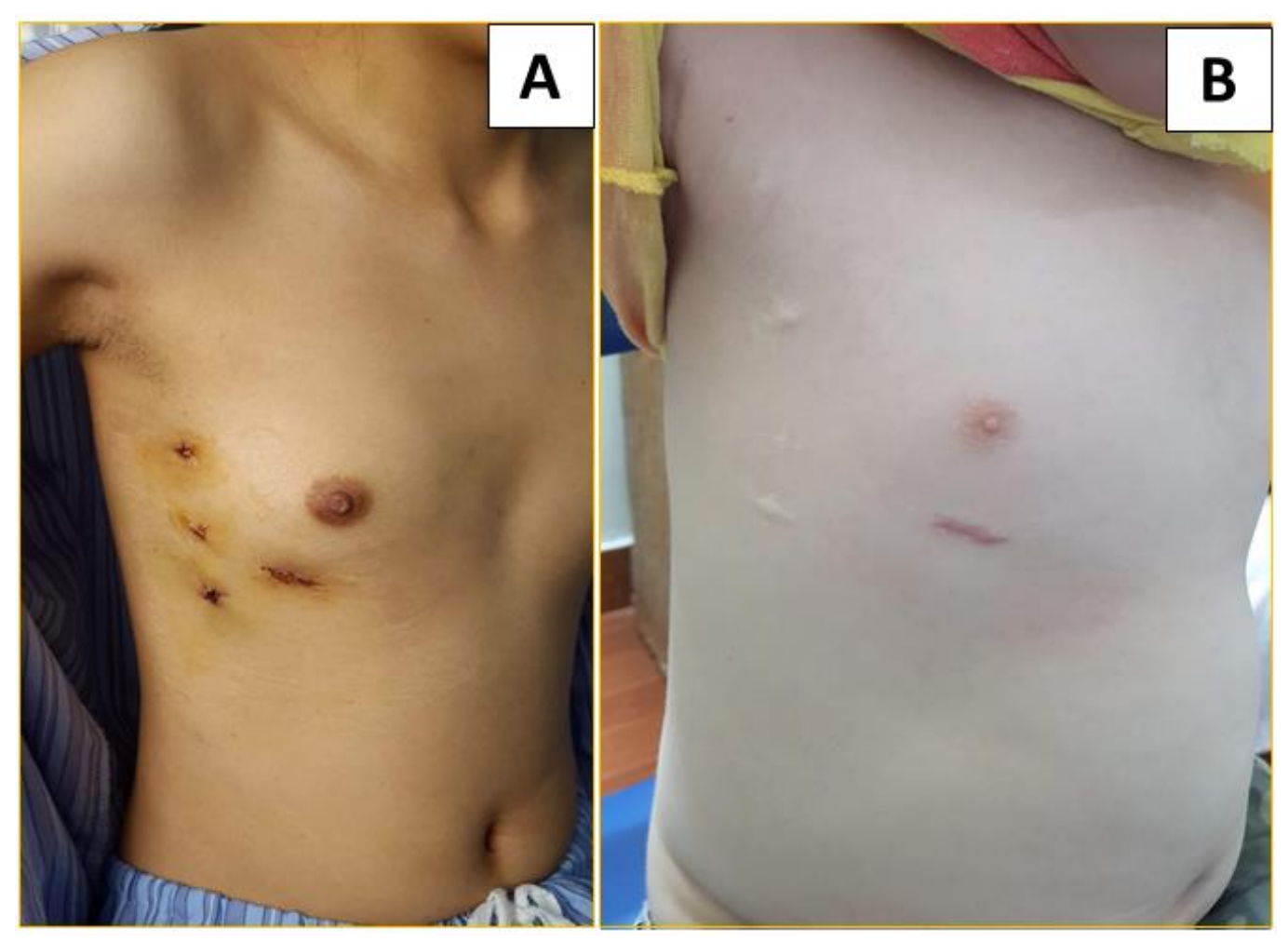

Hình 4. Sẹo mổ của bệnh nhân sau mổ sưa thông liên nhĩ nội soi toàn bộ; A, bệnh nhân nữ 24 tuổi trước khi ra viện; B, bệnh nhân nam 3 tuổi sau mổ 2 năm. 
Thiết lập tuần hoàn ngoài cơ thể (THNCT) ngoại vi là bắt buộc trong PTNSTB. Biến chứng hẹp, tắc ĐM đùi chung và ĐM chậu ngoài xuất hiện ngay sau mổ hoặc sau một thời gian theo dõi đã được ghi nhận với tỉ lệ $0,68 \%$ - 10\% [17, $\underline{18]}$, nguy cơ cao ở phụ nữ và trẻ nhỏ[19]. Nguyên nhân của biến chứng là do tổn thương lớp nội mạc mạch máu do đặt một ống thông lớn vào trong lòng một ĐM nhỏ. Bên cạnh đó, thiếu máu cấp chi dưới (do ống thông ĐM chặn hoàn toàn hoặc gần hoàn toàn dòng máu xuống nuôi chi dưới trong suốt quá trình mổ) là biến chứng rất nặng, hay gặp ở trẻ nhỏ. Chúng tôi sử dụng 2 giải pháp để khắc phục các biến chứng này: (1) đặt ống thông ĐM đùi gián tiếp qua đoạn mạch nhân tạo, và (2) sử dụng ống thông ĐM có kích thước nhỏ hơn so với ĐM đùi của bệnh nhân từ 2-4Fr để đặt trực tiếp. Sử dụng phối hợp hai kỹ thuật này giúp đảm báo (1) áp lực đường $Đ M$ không tăng cao, (2) không tổn thương nội mạc ĐM đùi chung và ĐM chậu ngoài, và (3) không thiếu máu nuôi chi dưới dù thời gian chạy máy kéo dài. Trong nghiên cứu này, chúng tôi ghi nhận hiện tượng tăng áp lực đường ĐM đòi hỏi phải đặt đường $\mathrm{ĐM}$ phụ với mục đích giảm áp. Hiện tượng này xảy ra ở nhóm bệnh nhân trưởng thành thấp hơn một cách có ý nghĩa thống kê so với nhóm bệnh nhân nhi $\left(13,9 \%\right.$ so với $60 \%, \mathrm{p}=2,5^{*}$ $10^{-21}$ ). Điều này là do ở trẻ nhỏ và bệnh nhân trẻ có hiện tượng co thắt mạch khá mạnh, xuất hiện ngay sau khi đặt ống thông hoặc sau một thời gian chạy máy [19]. Trong nghiên cứu này, chúng tôi có 20 bệnh nhân có cân nặng từ $15 \mathrm{~kg}$ đến $25 \mathrm{~kg}$ và 4 bệnh nhân có cân nặng từ $13,5 \mathrm{~kg}$ đến $15 \mathrm{~kg}$, một câu hỏi lớn được đặt ra là những bệnh nhân này có bị biến chứng hẹp/ tắc $\mathrm{ĐM}$ đùi sau mổ hay không với thời gian theo dõi dài hạn. Ở nhóm bệnh nhân nguy cơ cao này, chúng tôi không ghi nhận một trường hợp nào có hẹp/ tắc ĐM đùi trong khoảng thời gian theo dõi,(trung bình: 21,0 $\pm 6,0$ tháng; từ 12 đến 36 tháng).

Trong phẫu thuật tim đập, biến chứng đáng lo ngại nhất là tắc mạch khí. Pendse cùng cộng sự (2009), Thapmongkol cùng cộng sự (2012), và Ma cùng cộng sự (2012) đã có báo cáo về ứng dụng phẫu thuật nội soi sử dụng phương pháp phẫu thuật tim đập trong điều trị TLN [플 20, 21] . Trong các báo cáo này, các tác giả đã chứng minh được tính an toàn hiệu quả của phương pháp chống tắc mạch khí của mình. Từ gợi ý của những nghiên cứu đi trước đó, chúng tôi áp dụng và xây dựng những quy trình chống tắc mạch khí của mình[6]: (1) duy trì áp lực đường $Đ M$ cao (> $70 \mathrm{mmHg}$ ở bệnh nhân trưởng thành và > $50 \mathrm{mmHg}$ với bệnh nhân nhi) trong suốt thời gian chạy máy, (2) giữ cho nhĩ trái luôn đầy máu, (3) làm đầy khoang màng tim và màng phổi bằng $\mathrm{CO} 2$, và (4) đuổi khí bằng cách làm phồng phổi ngay trước khi đóng kín lỗ thông. Chúng tôi không ghi nhận trường hợp nào bị biến chứng tắc mạch khí liên quan đến phẫu thuật. Mặc dù sử dụng phương pháp phẫu thuật tim đập, Ma cùng cộng sự (2012) vẫn sử dụng kim gốc ĐMC để hút khí [5]. Tuy nhiên, đặt kim gốc ĐMC trong phẫu thuật tim ít xâm lấn làm tăng nguy cơ chảy máu sau mổ [22]. CO2 với đặc điểm nặng hơn không khí và có khả năng hòa tan nhanh trong nước, đã được chứng minh là phương pháp chống tắc mạch khí an toàn, hiệu quả, và có thể thay thế các phương pháp đuổi khí truyền thống [4, 23] . Chúng tôi đã tiến hành siêu âm thực quản để theo dõi khí trong thất trái, gốc ĐMC và hoạt động của 
van ĐMC trong suốt quá trình vá TLN ở 10 bệnh nhân trưởng thành. Chúng tôi thấy rằng van ĐMC gần như luôn ở trạng thái đóng, và không có bóng khí trong thất trái cũng như gốc ĐMC. Từ đó chúng tôi thấy rằng kim gốc ĐMC là không cần thiết và phương pháp chống tắc mạch khí của chúng tôi là an toàn.

Nghiên cứu của chúng tôi có 3 bệnh nhân (chiếm 2,4\%) có tình trạng rung nhĩ trước mổ. Ba bệnh nhân này có tuổi lần lượt là $54,55,62$ tuổi, đều bị tăng áp lực ĐMP nặng và đều bị hở VBL nhiều. Tỉ lệ $2,4 \%$ này thấp hơn nhiều so với tỉ lệ cuồng nhĩ/ rung nhĩ trong nghiên cứu ở Toronto (1999) [24] và nghiên cứu ở Berlin (1999) [25] (lần lượt là $19 \%$ và $27 \%$ ).Trong quá trình theo dõi với thời gian theo dõi trung bình là $16 \pm 8,2$ tháng, chung tôi không ghi nhận bệnh nhân nào xuất hiện cuồng nhĩ/ rung nhĩ mới. Berger cùng cộng sự (1999) đã chỉ ra rằng cuồng nhĩ/ rung nhĩ mới sau mổ đóng thông liên nhĩ chỉ gặp ở bệnh nhân $>40$ tuổi và tỉ lệ xuất hiện rung nhĩ mới ở bệnh nhân $>60$ tuổi lên tới 48\%[25]. Trong nghiên cứu này, tác giả sử dụng Holter điện tim $24 \mathrm{~h}$ để theo dõi nhịp tim của bệnh nhân tại các thời điểm: trước mổ, 3 ngày đầu sau mổ, trước ra viện và những lần khám lại. Tỉ lệ cuồng nhĩ/ rung nhĩ trước mổ và sau mổ của chúng tôi thấp do thời gian theo dõi sau mổ còn ngắn và chúng tôi chỉ theo dõi bệnh nhân bằng điện tim 12 chuyển đạo. Vì lý do đó những rối loạn nhịp nhĩ có thể chưa xuất hiện hoặc bị bỏ sót. Berger nhấn mạnh sự khác biệt giữa cuồng nhĩ và rung nhĩ trước mổ: cuồng nhĩ trước mổ có tỉ lệ trở về nhịp xoang sau mổ lớn hơn so với rung nhĩ trước mổ (tỉ lệ lần lượt là 55\% so với 12\%, p<0.04)[26].Rung nhĩ là yếu tố nguy cơ gây nhồi máu não, được cho rằng chịu trách nhiệm cho 19-57\% trường hợp tử vong muộn ở bệnh nhân TLN[27]. Nyboe cùng cộng sự (2015) thấy rằng việc đóng lỗ TLN ở bệnh nhân đã có biến chứng rung nhĩ không làm giảm tỉ lệ nhồi máu não; nguy cơ này được kiểm soát chủ yếu bằng sử dụng thuốc chống đông[27].

Berger cùng cộng sự cũng ghi nhận một trường hợp TLN/ rung nhĩ đã được đóng TLN và điều trị chống đông đủ liều vẫn bị xuất hiện nhồi máu não[26]. Từ đó dẫn tới xu hướng điều trị triệt để rối loạn nhịp nhĩ ở bệnh nhân TLN. Một lần nữa vai trò của chẩn đoán phân biệt trước mổ giữa cuồng nhĩ, nhịp nhanh nhĩ do vòng vào lại với rung nhĩ lại được nhắc đến. Mavroudis cùng cộng sự (2004) đã đưa ra chỉ định: (1) phẫu thuật Maze nhĩ phải (right-sided Maze procedure) được chỉ định cho cuồng nhĩ và nhịp nhanh nhĩ do vòng vào lại, và (2) phẫu thuật Cox - Maze III được chỉ định cho những bệnh nhân rung nhĩ[28]. Stulak cùng cộng sự (2006) chứng minh phẫu thuật Maze nhĩ phải an toàn và có hiệu quả làm giảm tỉ lệ tái phát cuồng nhĩ/ rung nhĩ [29]. Trong thời gian tới, chúng tôi sẽ quan tâm hơn tới những phẫu thuật rối loạn nhịp nhĩ đồng thời với PTNSTB sửa TLN.

Trong nghiên cứu của chúng tôi thời gian phẫu thuật trung bình và thời gian chạy máy trung bình lần lượt là: $219,4 \pm 56,6$ và $116,5 \pm 44,7$ phút. Kết quả này không có sự khác biệt so với kết quả trong nghiên cứu gộp, đa trung tâm thực hiện bởi Yao cùng cộng sự (2013)[30]; trong đó thời gian chạy máy trung bình là 105,2 phút. Thời gian thở máy và thời gian nằm viện sau mổ trong nghiên cứu của chúng tôi cũng không có sự khác biệt so với kết quả trong báo cáo của Yao. 
Trong cả 3 nhóm nghiên cứu, chúng tôi đều ghi nhận đường cong đào tạo có ý nghĩa về thời gian phẫu thuật và thời gian chạy máy. Đường cong của nhóm I có ý nghĩa nhất với $\mathrm{R}^{2}=0.62$ và 0,85 lần lượt cho thời gian phẫu thuật và thời gian chạy máy. Các thông số về thời gian mổ giảm còn một nửa ở bệnh nhân thứ 20 . Trong 20 bệnh nhân đầu, đường cong có dạng dựng đứng (giảm nhanh). Trong khi đó từ bệnh nhân thứ 20 trở đi, đường cong vẫn đi xuống nhưng có dạng thoải (giảm chậm). Ở nhóm II và III, đường cong đào tạo ít ý nghĩa hơn; các thông số về thời gian mổ giảm còn một nửa ở bệnh nhân thứ 15 . Thời gian đào tạo của 2 nhóm này ngắn hơn so với nhóm $\mathrm{I}$ do thời gian đầu nghiên cứu, chúng tôi chỉ phẫu thuật trên những bệnh nhân không phải sửa VBL; khi thao tác nội soi đã thành thục hơn và quen với phẫu trường chúng tôi mới mở rộng chỉ định ra nhóm $\mathrm{BN}$ có sửa VBL. Bonaros cùng cộng sự (2006) đã chỉ ra cần thời gian đào tạo ngắn (10 bệnh nhân) cho PTNSTB sửa TLN có hỗ trợ của robot[1]. Qua đó thấy rằng, với sự hỗ trợ của robot về kỹ thuật, thời gian đào tạo của phương pháp PTNSTB đã được rút ngắn lại còn một nửa. Mặc dù vậy, ở một trung tâm lớn, thời gian đào tạo trên 20 bệnh nhân không phải quá dài và hoàn toàn khả thi trong điều kiện Việt Nam.

\section{KẾT LUẬN}

PTNSTB không robot hỗ trợsửa TLN là phương pháp an toàn, hiệu quả với thời gian đào tạo ngắn; có thể dễ dàng áp dụng tại các trung tâm phẫu thuật tim khác trong nước và quốc tế.

\section{TÀI LIẸU THAM KHẢO}

1. Bonaros, N., et al., Robotically assisted totally endoscopic atrial septal defect repair: insights from operative times, learning curves, and clinical outcome. Ann Thorac Surg, 2006. 82(2): p. 687-93.

2. Morgan, J.A., et al., Robotic techniques improve quality of life in patients undergoing atrial septal defect repair. Ann Thorac Surg, 2004. 77(4): p. 1328-33.

3. Senay, S., et al., Robotic atrial septal defect closure. Multimed Man Cardiothorac Surg, 2014. 2014.

4. Xiao, C., et al., Totally robotic atrial septal defect closure: 7-year single-institution experience and follow-up. Interact Cardiovasc Thorac Surg, 2014. 19(6): p. 933-7.

5. Ma, Z.S., et al., Totally thoracoscopic closure for atrial septal defect on perfused beating hearts. Eur J Cardiothorac Surg, 2012. 41(6): p. 1316-9.

6. Dang, Q.-H., et al., Totally Endoscopic Cardiac Surgery for Atrial Septal Defect Repair on Beating Heart Without Robotic Assistance in 25 Patients. Innovations:Technology and Techniques in Cardiothoracic and Vascular Surgery, 2017. 12(6): p. 446-452.

7. Liu, G., et al., Totally thoracoscopic surgical treatment for atrial septal defect: midterm follow-up results in 45 consecutive patients. Heart Lung Circ, 2013. 22(2): p. 88-91.

8. Van der Linde, D., et al., Birth prevalence of congenital heart disease worldwide: a systematic review and meta-analysis. J Am Coll Cardiol, 2011. 58(21): p. 2241-7. 
9. Carpentier, A., et al., [Computer assisted open heart surgery. First case operated on with success]. C R Acad Sci III, 1998. 321(5): p. 437-42.

10. Warinsirikul, W., et al., Closure of atrial septal defects without cardiopulmonary bypass: The sandwich operation. The Journal of Thoracic and Cardiovascular Surgery, 2001. 121(6): p. 1122-1129.

11. Ma, Z.S., et al., Totally thoracoscopic repair of atrial septal defect without robotic assistance: a single-center experience. J Thorac Cardiovasc Surg, 2011. 141(6): p. 1380-3.

12. Wang, F., et al., Totally thoracoscopic surgical closure of atrial septal defect in small children. Ann Thorac Surg, 2011. 92(1): p. 200-3.

13. Đặng Quang Huy, Nguyễn Ngọc Anh, and Lê Ngọc Thành, Phẫu thuật nội soi toàn bộ tim đập vá thông liên nhĩ ở bệnh nhân nũ 11 tuổi. Tạp chí phẫu thuật tim mạch và lồng ngực Việt Nam, 2016. 15: p. 28-32.

14. Đặng Quang Huy, et al., Phẫu thuật nội soi toàn bộ không có robot hỗ trợ, tim đập vá thông liên nhĩ ở 13 bệnh nhân. Tạp chí phẫu thuật tim mạch và lồng ngực Việt Nam, 2016. 15: p. 3-9.

15. Huy, Đ.Q., Phẫu thuật nội soi toàn bộ, không robot hố trơ', tim đập vá thông liên nhĩ ơ trẻ nhỏ. Tạp chí phẫu thuật tim mạch và lồng ngực Việt Nam, 2017. 17.

16. Huy, Đ.Q., Phẫu thuật nội soi toàn bộ không có robot hồ trợ, tim đập vá thông liên nhĩ. Kinh nghiệm ở một trung tâm. Tạp chí phẫu thuật tim mạch và lồng ngực Việt Nam, 2017. 18.

17. Rosu, C., et al., Preoperative vascular imaging for predicting intraoperative modification of peripheral arterial cannulation during minimally invasive mitral valve surgery. Innovations (Phila), 2015. 10(1): p. 39-43.

18.Sagbas, E., et al., Mid-term results of peripheric cannulation after port-access surgery. Interact Cardiovasc Thorac Surg, 2007. 6(6): p. 744-7.

19. Dang, H.Q., H.T. Le, and L.T.H. Ngo, Totally endoscopic atrial septal defect repair using transthoracic aortic cannulation in a 10.5kg-boy. International journal of surgery case reports, 2018. 52: p. 103-106.

20. Thapmongkol, S., et al., Beating heart as an alternative for closure of secundum atrial septal defect. Asian Cardiovasc Thorac Ann, 2012. 20(2): p. 141-5.

21. Pendse, N., et al., Repair of atrial septal defects on the perfused beating heart. Tex Heart Inst J, 2009. 36(5): p. 425-7.

22. Cheng, Y., et al., Totally endoscopic congenital heart surgery compared with the traditional heart operation in children. Wien Klin Wochenschr, 2013. 125(21-22): p. 704-8.

23. Chaudhuri, K., et al., Carbon dioxide insufflation in open-chamber cardiac surgery: a double-blind, randomized clinical trial of neurocognitive effects. J Thorac Cardiovasc Surg, 2012. 144(3): p. 646-653 e1.

24. Gatzoulis, M.A., et al., Atrial arrhythmia after surgical closure of atrial septal defects in adults. N Engl J Med, 1999. 340(11): p. 839-46.

25. Berger, F., et al., Incidence of atrial flutter/fibrillation in adults with atrial septal defect before and after surgery. Ann Thorac Surg, 
1999. 68(1): p. 75-8.

26. Berger, F., et al., Arrhythmias in patients with surgically treated atrial septal defects. Swiss Med Wkly, 2005. 135(11-12): p. $175-8$.

27. Nyboe, C., et al., Atrial fibrillation and stroke in adult patients with atrial septal defect and the long-term effect of closure. Heart, 2015. 101(9): p. 706-11.

28. Mavroudis, C., B.J. Deal, and C.L. Backer, Surgery for arrhythmias in children. Int J Cardiol, 2004. 97 Suppl 1: p. 39-51.
29. Stulak, J.M., et al., Right-sided Maze procedure for atrial tachyarrhythmias in congenital heart disease. Ann Thorac Surg, 2006. 81(5): p. 1780-4; discussion 1784-5.

30. Yao, D.K., et al., Totally endoscopic atrial septal repair with or without robotic assistance: a systematic review and metaanalysis of case series. Heart Lung Circ, 2013. 22(6): p. 433-40. 